developed or evaluated. We conducted an evaluation of a home visiting model of early intervention developed by the Illawarra Aboriginal Medical Service as an injury prevention program targeting disadvantaged Aboriginal families with young children aged $0-5$ and their families living in an urban region of NSW.

Methods The evaluation conducted between January 2014 and June 2015 included process, impact and outcomes components. Data collection included: routinely collected program data; semistructured interviews with 35 individuals; and a family worker survey. All data was coded thematically and a framework analysis applied using NVivo software. Capacity building activities were conducted throughout the period.

Results The Program addressed the need for a culturally appropriate safety program delivered by Aboriginal family workers to vulnerable families. Clients expressed a high degree of satisfaction with the family workers' delivery of the program and the holistic model of service provision offered. Key results included: increased engagement in safety programs; improved child safety knowledge and skills; increased accessibility for parents/carers, children and families to services; improved attitudes to home and community safety; changes in the home safety environment. The evaluation provided opportunities for collaboration between researchers and the Aboriginal medical service and capacity building for the Aboriginal family workers.

Conclusions The 'Safe Homes Safe Kids' program offers a promising program for addressing unintentional injury to vulnerable Aboriginal children in urban areas.

\section{PROMOTING SAFETY IN THE MOST HAZARDOUS LOCATION THROUGH A HOME SAFETY DEMONSTRATION SITE}

Katherine Celenza. Kidsafe Western Australia, Australia

\subsection{6/injuryprev-2016-042156.236}

Background More children die from injury than from cancer, asthma and infectious diseases combined and the most common location for injuries to occur are within the home setting. Children, specifically those under five spend majority of their time within the home, it is the place where parents feel comfortable, confident and are aware of all of its features. Kidsafe Western Australia houses a Safety Demonstration House, established in 2006 and provides interactive displays to target injury prevention strategies and approaches to prevent child injury within the home.

Objective This paper will outline the services offered through the safety demonstration house and how it is helping to raise awareness and provide interactive opportunities to see injury prevention in practice. The Kidsafe WA Safety Demonstration house provides a range of services to highlight points of potential injury in the home and methods of injury prevention. The demonstration site provides physical examples of particular home settings, applied safety latches, barriers and child resistant products that participants can view, touch and test. The site also provides photographic and interactive information to align with the displays and products provided.

Results The Kidsafe WA Safety Demonstration House runs services targeting parents and carers, students, professionals and anyone interested in child safety seeing 220 participants specifically utilising the house within the last year. These services include self guided and guided tours, mobile information provided through Quick Response codes and an online safety demonstration house.
This paper will also outline where the safety house started, how it has developed and where it is heading. With a new building to soon house the site a purpose built area will see a new purpose build updated and revamped Kidsafe WA Safety Demonstration House.

Conclusions The aim of the Kidsafe WA Safety Demonstration House is to provide interactive and physical displays and information to increase awareness and knowledge of parents, carers, health professionals and the community in regards to childhood injuries. This is intended to promote child safety measures and to ultimately reduce the incidence of child injuries that occur within the home.

\section{THE PREVALENCE OF HOME RELATED INJURIES AMONG CHILDREN UNDER FIVE ATTENDING PRESCHOOL EDUCATION ESTABLISHMENTS IN LITHUANIA}

1,2Justina Racaite, 'Gene Surkiene. 'Vilnius University Faculty of Medicine Institute of Public Health, Lithuania; ${ }^{2}$ Centre for Health Education and Disease Prevention, Lithuania

\subsection{6/injuryprev-2016-042156.237}

Background Babies, toddlers and little children spend most of their time at home. Because of undeveloped instinct of self-protection they usually get injured there. Some of the injuries are small and some are serious enough to require a visit to an emergency department. According to the State Deaths and their Causes Register during 2014 due to unintentional accidents (ICD-10-AM) W00-X59) in Lithuania were 10 deaths of children 0-5 years old. During last five years (2010-2014) 68 children 5 years and younger died in Lithuania because of the same reasons. According to the Lithuanian Trauma and Accidents Monitoring System during 2014 were registered 12043 (22,78/1000 inhabitants) cases of unintentional accidents (ICD-10-AM W00-X59) which required to visit emergency department and 2,571 (4,86/ 1000 inhabitants) cases then children were hospitalised for the same reason. All those injuries happened at home. Because of that, the aim of this research was to evaluate the prevalence of home related injuries among children under five attending preschool education establishments in Lithuania.

Methods Anonymous questionnaires were given to parents/ adopters of children under five who lived in 23 Lithuanian districts municipalities. The final study sample was of 1047 respondents. Methods of the statistical analysis were: descriptive statistics; for hypothesis testing were used Pearson $\mathrm{Chi}^{2}$ or Fisher exact tests; odds ratio for evaluation of risk and preventive factors were counted. $\mathrm{p}<0.05$ was considered statistically significant.

Results The prevalence of home injuries was $64.3 \%$; 95\% CI: [61.3-67.1]. The most common injuries were fall $(59.6 \%$; 95\% CI: [55.8-63.2]), cut/prick (41.2\%; 95\% CI: [37.5-44.9]), burn/scald (24.7\%; 95\% CI: [21.5-28]), choking/suffocation (15.5\%; 95\% CI: [13.0-18.4]). Most of the time during the injury child were supervised by an adult (>80\% cases). In cases then the parents/adopters let the children play in the yard/playground, without adult supervision, the risk of fall was 1.92 time bigger (95\% CI: [1.39-2.61]; $\mathrm{p}<0.0001$ ), in cases then parents/ adopters let the children to use kitchen appliances, without adult supervision, risk of burn/scald was 2,17 time bigger (95\% CI: [1.05-4.49]; $\mathrm{p}=0.02)$, in cases then parents/adopters let the children play with pet, without supervision of adult, the risk of pet injury was 3,05 time bigger (95\% CI: [1.77-5.29]; $\mathrm{p}<0.0001)$. The risk of injury is smaller if there is enough 
information for the parents/adopters about child home safety $(\mathrm{OR}=0.56 ; 95 \% \mathrm{CI}:[0.38-0.82], \mathrm{p}=0,0001)$ and the risk to cut/prick is smaller if sharp things are out of reach of children $(\mathrm{OR}=0.6 ;$ (95\% CI: [0.46-0.80]; $\mathrm{p}=0.0001)$.

Conclusions The prevalence of home injuries among children under five was $64,3 \%$. 2) The most common injuries are fall, cut/ prick, burn/scald and choking/suffocation. 3) Most often injuries occur then child are supervised by an adult. 4) Storage of sharp things out of reach of children and enough information for parents/adopters about home safety are preventive factors. Letting children play in the yard/playground, to use kitchen appliances, to play with pets without adult supervisions are home injuries risk factors.

\section{WATER HEROES - WATER SAFETY SKILLS FOR KIDS}

${ }^{1}$ Kristiina Jakobsson, ${ }^{2}$ Riitta Vienola, ${ }^{3}$ Tero Savolainen, ${ }^{3}$ Kristiina Heinonen, ${ }^{1}$ Sari Turunen. ${ }^{1}$ Finnish School Sport Federation; ${ }^{2}$ Arcada, University of Applied Sciences, Finland; ${ }^{3}$ Finnish Swimming Teaching and Lifesaving Federation

\subsection{6/injuryprev-2016-042156.238}

Background Water is a big part of the life style in Finland, "the land of a thousand lakes". The geographical and cultural features motivate the Finns to learn to swim. However, the statistics on causes of death reveal that among children (0-17) in Finland, drownings are the second largest group among fatalities due to accidents (Finnish Safety Investigation Authority 2012). The project "Water Heroes" was created for children, teachers and parents to help them to enjoy swimming and other water activities in a safe way.

Objective The three year project Water Heroes was launched in 2015. Its main goals are 1) to distribute information and inspire children and young people to spend time in and around water in a safe way, 2) to create a teacher handbook including different indoor and out-door models for the teacher to carry out various activities in conjunction with different school topics, 3) to advise parents on how to support their children in learning swimming and other water related skills safely. The project is led by the Finnish School Sport Federation and financed by Reijo Rautauoma Foundation.

Results During the first year, the project reached almost 3000 children and their teachers during the tour that stopped in five cities. In Helsinki the event was part of the European Week of Sport. Feedback from the participants has been positive and teachers found the events useful. Project has also received media attention. The experiences from the first events will be used to develop project activities and materials in the future. An online handbook for teachers will be published in the beginning of 2016.

Conclusions It is important to have different kind of strategies to tackle the drowning problem as well as to promote water activities in a safe way. Action-based projects seem to work well with school children. In addition, the learning-by-doing - model supports well the new fundamentals of Physical Education 2016, issued by the Finnish National Board of Education.

\section{SURVEILLANCE OF TOXIC EXPOSURES TO LIQUID LAUNDRY DETERGENTS IN PODS IN ITALY}

${ }^{1}$ Franca Davanzo, ${ }^{2}$ Laura Settimi, ${ }^{3}$ Felice Giordano, ${ }^{2}$ Laura Lauria, ${ }^{1}$ Anna Celentano, ${ }^{1}$ Fabrizio Sesana. 'National Poison Control Centrein Milan, Niguarda Cà Granda Hosptal, Italy; ${ }^{2}$ Italian National Institute of Health (ISS), Rome, Italy; ${ }^{3}$ Department of Public Health and Infectious Diseases, Sapienza University, Rome

\subsection{6/injuryprev-2016-042156.239}

Background Previous investigations have shown that liquid laundry detergents in pods have the potential to cause corrosive eye damages, pulmonary toxicity and serious laryngopharyngeal injuries. In Italy, different actions had been undertaken to prevent hazardous exposures in young children. The present study is mainly aimed at providing a preliminary evaluation of impact of these preventive measures.

Methods Exposures to laundry detergents involving children aged $<5$ years occurred during 2010-2014 were extracted from the National Poison Control Centre in Milan (NPCCM). The main characteristics of cases exposed to the two main categories of laundry detergents, i.e., liquid laundry detergents in pods (LDPs) and traditional laundry detergents (TLDs) were compared by means of Pearson's $\mathrm{X}^{2}$ test or Fisher's exact test. The mean daily number of exposure to main category of laundry detergents by month and year, and quantity of LDPs sold by month and company, i.e., MC and OCs, as provided by industry, were used to calculate exposure rates, i.e., number of cases exposed to LDPs/millions of units sold/month by year and company. Changepoint analysis was used to determine significant changes in exposure occurrence during the study period. A change was considered significant when the level of confidence that the change actually occurred was $95 \%$ or higher, as estimated by bootstrapping technics. Significant change points were used to define preand post-change point periods.

Results In comparison to cases exposed to TDLs ( $\mathrm{n}=1,203$ ) those exposed to LDPs $(n=1,551)$ were more frequently treated at an hospital (68\% vs 41\%, p < 0.001), and suffered moderate/ high severity clinical effects $(13 \%$ vs $<1 \%$, p $<0.0001)$. During the study period, the number of cases exposed to pods changed from an average of 1.3 cases/day, observed in September 2010 November 2012, to an average of 0.6 cases/day, observed in December 2012-December 2014. The observed change was specifically driven by products from a major company whose average rates were 2.10 cases/million units sold before December 2012, and 0.97 cases/million units sold in the following period. The rate change occurred four months after this company started selling its brands in obscure outer-packaging.

Conclusions The present study indicates that reducing visibility of LDPs could be associated with about a 50\% decrease of incidents among young children. However, considering that these products are strongly associated with severity of poisoning, further efforts should be devoted to prevent hazardous exposure and reduce the intrinsic toxicity of mixtures in pods.

\section{CHILD POISONING RISK DURING MATERNAL DEPRESSION AND ANXIETY EPISODES: SELF-CONTROLLED CASE SERIES}

Ruth Baker, Denise Kendrick, Elizabeth Orton, Laila J Tata. The University of Nottingham, UK

10.1136/injuryprev-2016-042156.240 